International Journal of Social and Educational Sciences, 2017

Uluslararası Sosyal ve Eğitim Bilimleri Dergisi, 2017

VOL. 4, NO. 7, 43-62

http://dx.doi.org/10.20860/ijoses.287863

\title{
Eğitim Örgütlerinde Bilgi Uçurma Sürecinin Yönetilmesi*
}

\section{Managing the Whistleblowing Process in Educational Organizations}

\section{Ali Baltacı}

Milli Eğitim Bakanlığı, Ankara, Türkiye

\begin{abstract}
Özet
Bilgi uçurma (whistleblowing), etik ve hukuki değerlere aykırılıkları bildirme davranışı olarak tanımlanabilir. Bilgi uçurma olayını gerçekleştiren kişi ise bilgi uçuran (whistleblower) olarak adlandırımaktadır. Bilgi uçurma kavramı örgüt içinde ve dışında, aktif ya da pasif olarak gerçekleşebilen bir süreçtir. Bilgi uçurma süreci esasen bireysel seçim ve karar alma süreçlerine benzemektedir. Bilgi uçurma sürecinin yönetilmesi, etik açıdan saydam bir örgüt oluşturmak için elzemdir. Ancak sürecin bilgi uçuran ve hakkında ihbarda bulunulan kişi veya örgüt açısından farklı sonuçları olabilmektedir. Bu çalışmanın amacı, genelde örgütlerde ve özelde ise eğitim örgütlerinde yaşanan bilgi uçurma sürecinin belirlenmesidir. Alanyazın taraması şeklinde tasarlanan çalışmada bilgi uçurma kavramı, bilgi uçurma süreci ve söz konusu sürecin yürütülmesi ile eğitim örgütlerindeki durum analiz edilmeye çalışılmıştır. Çalışma sonucunda Türkiye'de bilgi uçurma kavramına henüz gerekli önemin verilmediği, bilgi uçurma süreçlerinin yönetilemediği ve bilgi uçuranların yeterince korunmadı̆̆ belirlenmiştir. Çalışma ile alanyazındaki önemli bir boşluk giderilmiş ve ileride yapılacak çalışmalar için bir kuramsal temel hazırlanmıştır. Çalışmanın alanyazına önemli bir katkı sağlayacağı umulmaktadır.

Anahtar Kelimeler: Bilgi Uçurma, Bilgi Uçuran, Bilgi Uçurma Süreci, Bilgi Uçurma Sürecinin Yönetilmesi, Eğitim Örgütleri.
\end{abstract}

\begin{abstract}
Whistleblowing is reporting behavior of contradictions to ethical and legal values that occurs in organizations. The person who carries out the whistleblowing event is called the whistleblower. The concept of whistleblowing is a process that can take place actively or passively in and out of an organization. Whistleblowing process is basically similar to individual selection and decision making processes. The governance of the whistleblowing process is essential for creating an ethically transparent organization. However, the process can have different results in terms of the whistleblower and the person or organization being reported. The aim of this study is to determine the whistleblowing process in general, in organizations and in particular in educational organizations. The whistleblowing concept, whistleblowing process and the situation in educational organizations have been tried to be analyzed. As a result of the study it has been determined that whistleblowing concept in Turkey is not yet given necessary importance, whistleblowing processes cannot be managed and whistleblowers are not adequately protected. A significant gap in the literature has been covered by from the study and a theoretical basis has been prepared for future studies. It is hoped that the study will make an important contribution to the literature.
\end{abstract}

Key Words: Whistleblowing, Whistleblower, Whistleblowing Process, Managing Whistleblowing Process, Educational Organizations.

CONTACT : Ali Baltacl, alibaltaci@meb.gov.tr

Geliş Tarihi \& First Received : 24.01.2017

Kabul Tarihi \& Accepted : :07.05.2017

* Bu çalışma Prof. Dr. Ali Balcı'nın danışmanlığında hazırlanan "Maarif Müfettişleri İle İlk ve Ortaokul Yönetici ve Öğretmenlerinin Bilgi Uçurma Davranışına İlişkin Görüşleri” başlıklı doktora tezinin bir bölümüne dayalı olarak hazırlanmıştır. 


\section{Giriş}

Bilgi uçurma kavramı son dönemde yönetim bilimi alanyazınında sıklıkla tartışılan bir kavramdır. Bilgi uçurma, örgütlerde gerçekleşen ve gerek örgüt çalışanları ve gerekse örgüt yöneticilerinin de dâhil olduğu etik ve hukuk değerlere aykırılıkları bildirme davranışıdır. Toplum içinde genellikle olumsuz bir imajı olan ve bilgi uçuran aleyhine sonuçları olan bilgi uçurma kavramı, genelde toplumda ve özelde ise örgütlerde etik değerlerin içselleştirilmesiyle birlikte önem kazanacaktır.

Çalışanlar, örgüt içerisinde gerek kendilerine karşı ve gerekse diğer çalışanlara karş1 sergilenen farklı türde etik davranışlarla karşılaşabilmektedirler. Etik davranışların aktarılması konusunda çalışanlar daha istekli davranırken, olumsuz ve etik dışı davranışlara şahit olduklarında genellikle sessiz kalma eğilimi göstermektedirler (Dozier ve Miceli, 1985). Bu durumun nedeniyse, etik olmayan ya da hatalı olan davranışların açığa çıkarılmasının, çalışanlar için sıklıkla olumsuz sonuçlarının olmasıdır (Alford, 2001). Çalışanlar, söz konusu davranışları diğer çalışanlara veya örgüt yönetimine haber verdiklerinde, yöneticiler ve diğer çalışanlar bu iletimi yapan çalışana çoğu kez sadakatsiz, ispiyoncu, gammaz gibi olumsuz yakıştırmalar yapmakta (Aselage ve Eisenberger, 2003) ve hatta işten çıkarılmaya kadar uzanan çeşitli durumlarla karşılaşabilmektedirler (De Maria, 1999). Oysa çalışanların şahit oldukları etik dışı eylemleri bildirmesi örgütsel yaşamın saydamlaşması açısından özellikle önemlidir (Aydın, 1998; Delmas, 2014).

$\mathrm{Bu}$ çalışmada öz itibariyle eğitim örgütlerinde gerçekleşen etik ve hukuk dışı durumların bildirilme sürecine ve bu sürecin yönetimine odaklanmıştır. Çalışma kavramın tüm ayrıntılarını tam olarak içeren bir mükemmelliğe sahip olmasa da eğitim örgütlerinde var olan durumu anlama ve yönetme noktasında bilime katkı sağlayacaktır.

\section{Bilgi Uçurma}

Bilgi uçurmanın ilk tanımı 1985'de Miceli ve Near tarafindan ifade edilmiştir. Near ve Miceli'e göre (1985) bilgi uçurma, yürürlükteki yasalara ve toplumun genelince kabul edilmiş etik ilkelere aykırı ve gayrimeşru eylem ve davranışları fark eden örgüt çalışanının, söz konusu eylem ve davranışlardan etkilenmiş olabilecek veya bu eylem ve davranışları engelleyebilecek örgüt ya da kişilere yaptığı bilinçli duyuru durumudur. Cross ve Tiller (1998), bilgi uçurmayı, örgüt çalışanın yaptığı bilinçli eylemler dizgesi olarak değerlendirmiş ve örgüt içinde yaşanan etik dış1 veya konusu suç olan durumların, yine bir örgüt çalışanı tarafindan istendik olarak ortaya çıkarılması olarak tanımlamıştır. Baltacı ve Balcı (2017b) ise çalışanların işyerlerindeki olumsuz durumları ve hatalı işlemleri fark ederek örgüt içindeki yetkili birimlere, örgütün bağlı olduğu kamu örgütlerine, medyaya veya sorunu çözebileceklerine inandıkları başka kişilere açıklama, şikâyet ya da ihbar yolu ile bildirmesi olarak tanımlamışlardır.

Örgütsel davranış çalışmalarında sıklıkla yer etmiş olan bilgi uçurma terimi için çeşitli dillerde de farklı bir karşılık geliştirilmemiş olup, farklı çalışmalarda söz konusu terimin İngilizce olarak kullanıldığı görülmektedir. Bu nedenle, terime ilişkin Türkçe isimlendirmenin bulunması özel çaba gerektirmektedir. Türkçe alanyazında konuyu inceleyen Aydın (2003) whistleblowing'i, "Bilgi Uçurma" şeklinde ifade etmiş, fakat başka isimlendirmelerin de bulunabileceğini kabul etmiştir. Alanyazında bulunan az sayıda çalışmada bilgi uçurma sözcüğü bir Türkçe karşılık aranmadan kullanılmaktadır (Aktan, 2006). Kelimenin tam ve tek sözcükten oluşan bir Türkçe karşıllı̆ı bulunmamakla birlikte gammazlama, muhbirlik veya jurnalcilik kelimeleri, bilgi uçurma ile gerçekleşen fiili, olumsuz gösteren terimler olduklarından uygun düşmemektedirler. Bir çalışanın örneğin, bir ilacın öldürücü yan etkilerinin gizlendiğini fark edip kamuoyunu uyarması, bir maden veya tersanede güvenlik önlemlerinin yeterince alınmadığının fark edilip ihbar edilmesi ile iş arkadaşlarının canını kurtarması olumlu bir nitelemeyi gerektirmektedir (Dozier ve Miceli, 1985).

Genel bir tanım olarak bilgi uçurma, örgüt içerisinde etik dışı durumların, örgüt üyelerince açığa çıkarılması durumudur (King, 1999). Alanyazında kavram, çalışanların örgüt içindeki 
görevlerini kötüye kullanma, görevlerini ihmal etme veya hukuk dışı eylemlerinin açığa çıarılması, duyurulması anlamına gelmektedir (Near, Rehg, Van Scotter ve Miceli, 2004). Başka bir anlamıyla bilgi uçurma, çalışanların örgüt içi direnişlerinin yeni bir desenidir ve çalışma ortamlarının daha insani bir biçimde örgütlenmesi için çalışan ile yönetim arasında süren amansız bir savaştır (Bouville, 2008).

\section{Bilgi uçuran}

Bilgi uçuran (whistleblower), örgüt içinden bilgi sızdıran iş görenlerdir (Near ve Miceli, 1985). Taylor ve Curtis'e göre (2010), bilgi uçurma kavramında olayın öznesi olan birey, yani bilgi uçuran, bildirme eylemine, örgütte şahit olunan edim ve eylemin örgüt içinde veya dişında başka birey veya örgütleri zarara uğratmaması için başvurmaktadır. Mağdur, bilgi uçurma yapan birey (bilgi uçuran) veya diğer örgüt çalışanları ve bazı durumlarda bütünüyle toplum da olabilmektedir. Ajzen'e göre (1991), bilgi uçuran, şahit olduğu etik dışı olay hakkında önemli bir verinin veya bilginin sahibidir. Bilgiyi elinde bulunduran bilgi uçuran, örgüt içinde halen çalışan veya daha önce çalışmış biri olabilir (Poitras, 2014). Bilgi uçurma yalnızca çalışanlar tarafından değil, fakat aynı zamanda eski çalışanlar, örgütü denetlemekle yükümlü kurumlar (ve sivil toplum kuruluşları tarafindan da yapılabilir (Dawson, 2000; Mesmer-Magnus ve Viswesvaran, 2005).

Bies ve Moag'a (1986) göre, bilgiyi elinde bulunduran kişi, söz konusu bilgiyi kendi kullanabileceği gibi diğer kişi ve örgütlere ileterek de söz konusu etik dışı durumun ifşa edilmesini sağlayabilir. Hassink, de Vries ve Bollen'e (2007) göre, bilgi uçurma eylemi özellikle ve resmi olarak denetim görevini yürüten kişilerden farklı olarak "gönüllü denetçiler" (volunteer auditors) kanalıyla da yapılabilmektedir. Bilgi uçuran, skandal, tehlike, suiistimal ve yolsuzluk durumlarında halkı ve kolluk güçlerini uyaran kişidir (DeGeorge, 1990). Bilgi uçuran, şikâyetin soruşturulmasında ve yanlış uygulamanın düzeltilmesinde yetkili olan bir kişi veya birime, belirli bir mesleki rol ile doğrudan ilişkili olarak, kendi özgür iradesi ve kamu yararı anlayışı ile açığa çıkaran duyarlı bir vatandaştır (Tsahuridu ve Vandekerckhove, 2008; Verschoor,2005; Davidson, Goodwin-Stewart ve Kent, 2005). Seiffert'e göre (2006), bilgi uçurma durumlarında, durumun if̧̧a edilmesi süreci bir "zorlama" hatta "zorunluluk" durumu değil aksine bir "gönüllülük" durumudur. Türkiye'de kamu görevlilerinin hukuk ve etik diş1 durumları ifşa etmeleri yasal olarak belirlenmiş 'suçu bildirmeme suçu' olarak bir zorunluluk belirlenmiştir. Bunun yanında dilekçe hakkı veya bildirimde bulunma sorumluluğu olarak da adlandırılan bir düzenleme ile bilgi uçuranlar örgütlerde meşrulaştırılmaya çalışılmıştır.

$\mathrm{Bu}$ tanımlardan hareketle bilgi uçuran kişi ilgili örgütte aktif olarak çalışan bir kişi olmalıdır. NSA çalışanı Edward Snowden örneğinde olduğu gibi bilgi uçuran kişi, bir örgütün çalışanı olan işçi, memur veya sözleşmeli personel olabilir. Hukuka veya etiğe aykırı iş ve işlemlerin gerçekleştiği örgütle ilişki içinde olmayan kişiler bilgi uçurma eyleminin dişında kalmaktadır. Ancak Jullian Assange örneğinde olduğu gibi örgüt dışında olan kişiler de önemli bilgi uçurma faaliyetleri içinde yer alabilirler. Yine de alanyazında, bilgi uçuran kişinin içeriden birisi (insider) olması veya örgüt içine erişimi sağlayabilen bir noktada bulunmasının önemli olduğu vurgulanmaktadır (Jubb, 1999). Bunun yanında bilgi uçuranların kimliklerini gizleyerek veya farklı kurum ve kişiler üzerinden bilgi akışı sağlayarak da örgütte yaşanan durumları ifşa etmeleri olasidir.

\section{Bilgi uçurmanın Kapsamı}

Bilgi uçurma eyleminin temel konusu hukuka ve etik değerlere aykırı işlem ve eylemlerdir. Hukuka aykırı davranışlar, öncelikle, yasal metinlere olan aykırılıklar veya yasal metinlerin alenen ihlal edilmesi olarak ele alınabilir ki bu bağlamda, toplumca belirlenen eğitim, sağlik ve güvenlik kurallarına, insanların doğumlarından itibaren veya sonradan sahip oldukları temel hak ve özgürlüklere aykırılık gibi eylemler akla gelebilir (Lennane, 1993). Ancak, hukuka aykırı 
davranışlar, bunların ötesinde yolsuzluk ve rüşvet başta olmak üzere her türlü suç ve kabahatleri, özellikle mali suç ve aykırılıkları (vergi kaçakçılığı, zimmet, hırsızlık, dolandırıcılık vb.), bir ürünün doğaya ve insan sağllğına verebileceği zarardan, eğitim, sağlik ve güvenlik alanındaki istismar ve ihmallere, rekabeti sınırlayan anlaşmalara, kişi hak ve özgürlüklerinin ihmal ve istismarına kadar her türlü olumsuzluğun açığa çıkarılması, bilgi uçurma kapsamında yer alır (Ahem ve McDonald, 2002; Baltac1, 2017c; Sims ve Keenan,1998). Bununla birlikte örgütlerde karşılaşılabilecek etik ihlaller de bilgi uçurmanın kapsamındadır.

Kişiler arasında kendiliğinden gerçekleşen enformel iletişimden kaynaklanan dedikodu kavramı da bilgi uçurma davranışı içerisinde ele alınabilir (Faunce, 2004). Bu noktada işgörenler örgüt içinde, enformel iletişim yöntemlerine başvurarak bazı etik ihlallerini çevrelerindeki kişilere aktarabilmekte (Aydın, 2006) ve bu yolla etik ihlale ilişkin belirgin bir bilgi akışı sağlanabilmektedir. Esasen enformel iletişim, söylenti veya dedikodu olarak tanımlayabileceğimiz, formel örgüt yapısında etkili iletişimin sağlanması noktasında önemli bir araç konumundadır (Banja, 1985). Devletin getirdiği düzenleme ve kurallar yanında, örgütlerin üyesi kurumların, mesleki örgütlerin, sivil toplum kuruluşlarının veya bizzat örgütün kendisinin koyduğu etik kurallara aykırılıklar da bilgi uçurma kapsamındadır. Alanyazında yapılan bazı tanımlardaki "ahlaka aykırı" davranışlar da bilgi uçurma kapsamına dâhil edilmektedir (Hwang, Staley, Te Chen ve Lan, 2008). Bireyin ahlak konusundaki sübjektif değerlendirmeleri ile bilgi uçurma eyleminin alanını çok genişletebilen bu yaklaşım sorunlu görünmektedir. Ahlak ve hukukun farklı kavram ve alanlar olduğu, hiç kimsenin kendi dini veya toplumsal ahlak anlayışıı başkasına benimsetmek ve uygulatmak hakkı olmadığı dikkate alınmalıdır (Read ve Rama, 2003). Bununla birlikte, açık bir hukuki veya etik kurallar dizgesine konu olmamış fakat aynı zamanda ahlak olgusunu rahatsız eden bazı davranışların bilgi uçurma eylemine konu olması mümkün olabilir (Macey, 2007).

\section{Bilgi Uçurma Süreci}

Örgütlerde bir çalışan, yönetici (okul müdürü, ilçe veya il yöneticileri vs.) ya da çalışma arkadaşlarının hukuka ve etik kurallara aykırı veya şüpheli uygulamalarına şahit olduğunda bu bilgiyi açıklarsa bilgi uçurma davranışını gerçekleştirmiş olacaktır. Özünde çalışanın bu tutumu bir çeşit sivil itaatsizlik durumu olabilir. Bu noktada sivil itaatsizlik üç kıstasa göre tanımlanır: (1) Eylem hukuk kuralları dışında tanımlanmış (yasadışı) olmalıdır, (2) eylem ahlaki bir nedenden dolayı yapılmalıdır, (3) eylem sakıncalı bulunan bir yasanın ya da uygulamanın değiştirilmesi için yapılmalıdır. Bunun da ötesinde sivil itaatsizlik yapan kişi etik kurallara ve hukukun üstünlügüne saygılı olmalı, itaatsizliği ile işlediği suçun getirdiği müeyyideyi kabul etmelidir. Çalışanlarca genellikle uygulanan yazılı ve sözlü iş kuralları, yönetimin kural ve uygulamalarıdır. Örgütün kuralları ahlaki nedenlerle çiğnendiğinde bunun adı bilgi uçurma, vatandaşlar hükümetin kurallarını çiğnediklerinde bunun duyurulması sivil itaatsizliktir (Hesch, 2009; Hunt, 2006; Kohn vd.2004). Bu noktada bilgi uçurma süreci yönetilmesi gereken bir süreci belirler.

Örgütsel süreç olarak değerlendirildiğinde bilgi uçurma üç unsuru içermektedir (Nam ve Nepak, 2007, 35):

- Hukuk veya Etik dişı uygulamayı açığa çıkaran kişi (bilgi uçuran) (Miceli ve Near,1994),

- Açığa çıkarılan konunun kamunun aleyhine olması (Armstrong, 2005; Banja, 1985).

- Açığa çıkarılan konunun örgütün aleyhinde olması (Larmer,1992).

Bilgi uçurma kavramı örgüt içinde ve dışında gerçekleşebilen bir süreçtir (Lewis, 2006). Kişinin, örgüt içinde herhangi bir hatalı davranış ve eylemle karşılaştığında, bu durumu bildirmesi için belirli bazı aşamaları tamamlanması gerekmektedir (Hunt, 2006). Şekil 1'de bilgi uçurana göre bilgi uçurma süreci yer almaktadır 


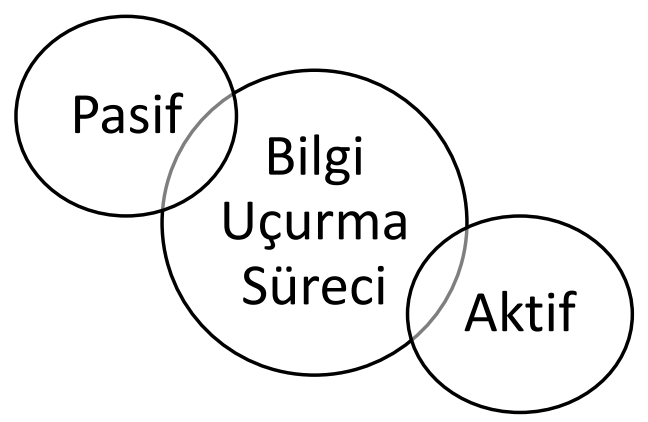

\section{Şekil 1. Bilgi Uçurana Göre Bilgi Uçurma Süreci}

Kaynak: Hunt (2006) ve Lewis (2006)' dan uyarlanmıştır.

Şekil 1'den hareketle bilgi uçurma aktif veya pasif olarak adlandırılan iki farklı süreçte gerçekleşmektedir (Near ve Miceli, 1995). Aktif bilgi uçurmada iş gören kendiliğinden hukuka aykırılığı ihbar veya şikâyet kanalı ile bildirirken, pasif olarak gerçekleşen bilgi uçurma sürecindeyse iş görenin bir şekilde bilgisine başvurulması durumunda etik ihlal veya hukuka aykırılığın açığa çıkarılması söz konusu olur (Rhodes ve Strain, 2004). Bilgi uçuran kişi adli makamlar, müfettiş, Başbakanlık Denetim Kurulu gibi bir makamın veya örgüt içi bir denetçinin sorgulamasında veya ifadesine başvurmasında söz konusu olay/durum/eylem veya olguya ilişkin bildiklerini anlatarak etik ihlalin veya hukuka aykırılığın ortaya çıkarılması da bu kapsamda değerlendirilmektedir (Lovell, 2003; DeGeorge, 1990; Balcı vd., 2012).

Bilgi uçuran, etik dışı davranışa ilişkin problemin çözülmesi sürecinde örgüt içi kanalların kapalı olduğu bir noktaya geldiğini düşündüğünde son olarak kendisine toplumsal veya örgütsel değerleri ve kuralları temel almakta, var olan ortak adalet anlayışına uygun olarak örgütteki etik ihlalini dış otoritelere sunmaktadır. Bu duruma sorunun çözülmesini sağlayacak örgüt içi yasal mekanizmalar denenip tüm yasal kanallar tükendikten sonra başvurulmaktadır. Bu eylemiyle bilgi uçuran, var olan örgütsel yapının esas bileşenlerine veya örgütsel norm ve kurallara açıkça karşı durmaz. Aksine, bilgi uçuran bu davranışı ile temel bileşenlerin, norm ve kuralların önemsenmemesinden duyduğu endişeyi göstermektedir. Bu haliyle bilgi uçurma, örgütsel gizliliğe aykırı, ancak yasal bir davranış ve eylemin gerçekleştirildiği etik bir sürecin ifadesidir (Keenan, 2007; Fidan ve Öztürk, 2015a; Kaptein, 2010). Şekil 2' de Miceli, Near ve Dworkin'in (2013) Bilgi Uçurma Süreci Modeli görülmektedir. 


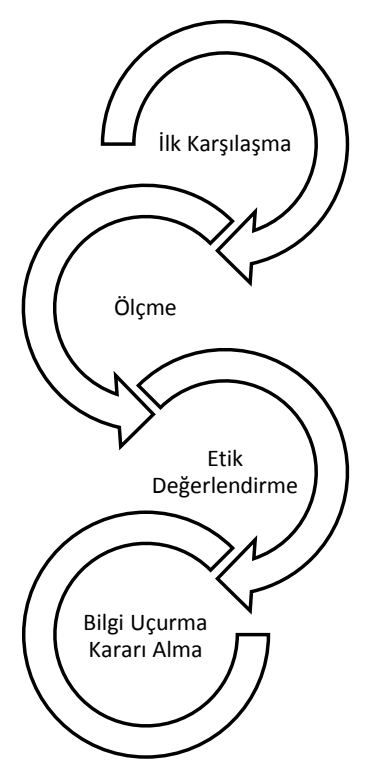

Şekil 2. Miceli, Near ve Dworkin'in Bilgi Uçurma Süreci Modeli

Kaynak: Miceli, Near ve Dworkin (2013)'den uyarlanmıştır.

Şekil 2'den hareketle, Miceli, Near ve Dworkin (2013), örgütte etik bir ihlal veya konusu suç oluşturabilecek bir davranışla karşılaşan çalışanın önce sessiz kaldığını ve söz konusu etik dışı davranışın sınırlarını anlamaya çalıştığını (ilk karşılaşma - first encounter), daha sonra karşılaştığı olayı kendi etik değerleriyle kıyasladığını ve belirli bir ölçüme gittiğini (comparison) ve ölçüm sonuçlarından hareketle duruma ilişkin etik bir değerlendirme yaptığını (ethical considerations), değerlendirme sürecinin ardından bilgi uçurma veya bilgi uçurmama yönünde karar aldığını (take a decision) belirlemektedir. Jubb (1999), bu sürece bilgi uçurulması halinde karşılaşılabilecek durumları da eklemiş ve bilgi uçuranın, bilgi uçurma davranışı sonrası bir geri bildirim (feedback) yaptığını ve aldığı kararın sonucunda isteği çıkarı elde edememesinin onun bir sonraki bilgi uçurma davranışını etkileyebileceğini bildirmiştir.

Trevino ve Nelson bilgi uçurma sürecini aşağıdaki şekilde sıralamaktadır (2004, 80-83):

- Etik ihlal veya hukuka aykırılığa şahit olduktan sonra ilkin örgüt yöneticisine başvurmak,

- Bilgi uçurma eylemine girişmeden önce durum hakkında aile veya yakın arkadaş ve akrabalar ile görüş alış verişi yapmak,

- Etik ihlalin veya hukuka aykırılığın bildirildiği örgüt yöneticisinin duyarsız kalması halinde durumu örgütteki (varsa) etik kurul, kamu denetçisi veya bildirim yapılabilecek yetkililer veya diğer yöneticilerle paylaşmak,

- Örgüt dışından otoritelerle iletişim kurmayı düşünmek,

- Örgüt dişından herhangi bir kişi, kurum veya medya organlarına başvurmak,

- Bilgi uçurmanin muhtemel bir sonucu olarak işten ayrılmak (O'Neill, 2013; Baltac1, 2016; Armstrong, 2005). 
Brown'a göre (2008), bilgi uçurma süreci beş aşamadan oluşan bir modeldir (Geleneksel Model). Birinci aşamada birey karşılaştığı etik dışı olayı bir sorun olarak fark eder. İkinci aşamada ise etik dışı olaya karşı nasıl bir davranış/hareket sergileyeceğini belirler (Chung, Monroe ve Thorne, 2004). Üçüncü aşamada birey eyleme geçme kararı alıp bu kararı uygular (Baltacı ve Balcı, 2017c; Organ, 1988). Sürecin rapora dökülmesi ile dördüncü aşama başlar (Park vd., 2008). Beşinci aşamada ise, kişi tam bir bilgi uçurana dönüşmüştür ve bu süreç bilgi uçuranın örgütün olaya verdiği tepkiyi değerlendirme ve gelecekte yapacakları için karar verme sürecini de kapsamaktadır (Carson, Ellen, Verdu ve Vokutch, 2008). Bilgi uçurma sürecini Şekil 3 yardımıyla izlemek mümkündür.

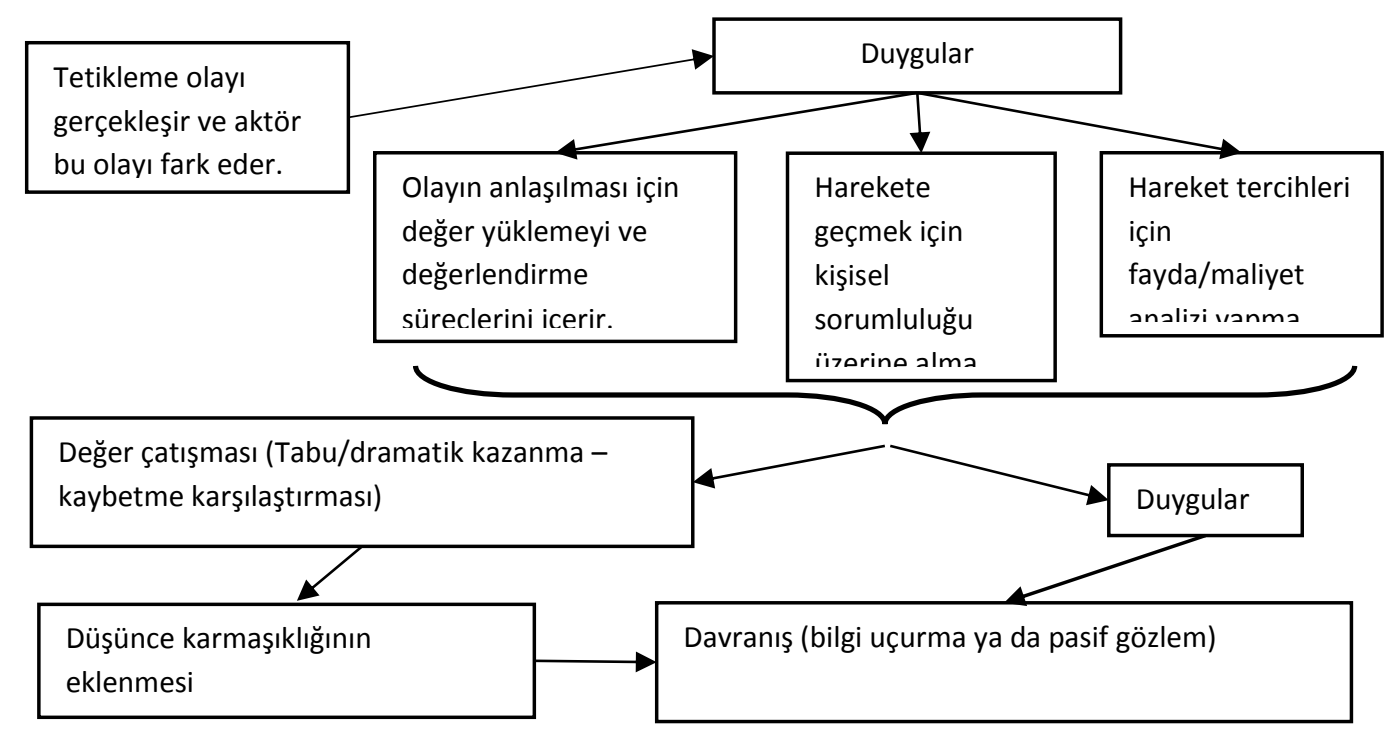

Şekil 3. Geleneksel Modele Göre Bilgi Uçurma Süreci

Kaynak: Henik (2008: 113)

Şekil 3'da görülebileceği üzere Brown'ın (2008) Modelinde, etik yargılama: Gözlemci müdahalesi, güç/bağımlılık ilişkileri ve öngörülen beklentiler çerçevesinde şekillenmektedir. Buna ek olarak, ikinci aşamada yer alan karar verme dört aşamada gerçekleşmektedir. Öncelikle birey, gözlenen davranışın sorun olup olmadığını yargılar, daha sonra, sonuçların ciddiyetinin değerlendirilmesini içerecek şekilde etik olmayan davranışla ilgili harekete geçmesinin gerekip gerekmediğini değerlendirir (Brown, 2008). Üçüncü olarak, kişisel olarak harekete geçmekten sorumlu olup olmadığını belirler ve son olarak da fırsat/maliyet analizi yapar; yararları ve intikam riskini de hesaba katarak, hangi hareketin yapılmasının olası ve uygun olduğunu değerlendirir (Lewis, 2006).

Geleneksel modelde her bir aşama çeşitli faktörlerden (sorunu fark etme, doğruyanlışı ayırt etme, bilgiye ulaşma ve ahlaki gelişimle ilgili olan grup normları vb.) etkilenmektedir (Chung, Monroe ve Thorne, 2004). Değerlendirme aşaması, davranışın özellikleri (örneğin: sıklığı) veya diğerlerinin davranışa tepkisi ile şekillenebilir. Sorun 
olan duruma karşılık vermede; kişisel sorumluluk üstlenme, ahlaki gerekçelendirme ile artabilir veya başka birçok gözlemci varsa, sorumluluğun dağıtılması yoluyla azaltılabilir (Henik, 2008; Alford, 2001).

Brown'ın (2008) Modeline göre, "Sosyal Bilgiyi İşleme Modeli" ile duygu/değer çatışması eklenerek Geleneksel Model'i geliştirmek mümkündür (Keenan, 2007). Böylece, bireylerin bilişsel değerleme süreci ile haksız olaylara karşı bilgi uçurma davranışlarının farklı duygusal durumlarda nasıl sonuçlanabileceğini belirlemek mümkün olabilecektir (Ernst ve Young, 2010; Coram, Ferguson ve Moroney,2008). Delmas (2014) bilgi uçurma eyleminin gerçekleşmesi temel özelliklerini şöyle siralamaktadır:

1. Örgüt içindeki hukuk veya etik dışı durumun örgüte veya topluma maliyeti zarar verici boyutlarda ise,

2. Bilgi sahipleri bu husustaki endişelerini örgüt yöneticilerine iletmiş iseler,

3. Bilgi sahipleri yetkililere konuyu iletip, onlardan yeterli ilgi görememişler ve çaresiz durumda kalmışlarsa,

4. Bilgi uçuran, hatalı davranışa ilişkin elindeki ikna edici delilleri yetkili kişiye iletmiş veya sunmuş ise,

5. Bilgi uçuran, hatalı davranış veya eylemi kamuoyunun bilgisine sunarak söz konusu hatalı durumun sonlanacağına inanıyor ise.

Bu noktada Bowie (1982) tarafından belirtilen şartlar da önemlidir:

- Bilgi uçuran, olayı örgüt dişı otoritelere bildirmeden önce örgüt yönetimine iletmek için tüm çabayı sergilemiş olmalıdır.

- Bilgi uçuran, olaya ilişkin elindeki delilleri, örgüt içinde güvendiği ve inandığ bir yetkili ile paylaşmış olmalıdır.

Bowie (1982) bilgi uçurmanın meşru bir eylem olabilmesi için aşağıda özetlenen altı temel özelliğinin var olması gerekliliğini savunmaktadır:

1. Bilgi uçurma davranışı kabul edilebilir etik güdülere dayanmalı ve bu güdüler, başkalarına zarar vermeyi engelleme amacı taşımalıdır.

2. Bilgi uçuran, bilgiyi kamuya açıklamadan önce etik olmayan davranışları engelleme konusunda örgüt içindeki mevcut tüm yöntemlerin hepsini kullanmış olmalidir.

3. Bilgi uçuran, mantıklı bir insanı ikna edecek kadar güçlü delillere sahip olmalidir.

4. Bilgi uçuran, çiğnenen kuralların sonuçlarının ciddi tehlike arz ettiği konusunda emin olmalıdır.

5. Bilgi uçuran, etik ihlalleri açıklamanın veya bundan kaçınmanın kişisel sorumluluklarına uygun davranmalıdır.

6. Bilgi uçuranın, vereceği kararın ve atacağı adımın makul bir başarı şansının olması gerekmektedir.

Bilgi uçurma sürecinin örgüt yönünden olumlu sonuçları da söz konusudur. Öncelikle çalışanın elde ettiği bilgiyi, örgüt yöneticilerine iletmesiyle örgütün iç denetim mekanizmasına işlerlik kazandırılması ve örgütteki uygulamaların gözden 
geçirilmesine imkân sağlaması söz konusudur (Davidson, Goodwin-Stewart ve Kent,2005). Bunun yanında örgütün kendi hakkında ifşa edilen bilginin oluşturabileceği olumsuz ortamı önlemek için daha özenli ve koordineli çalışması ve bir iç bakış kazanması da mümkün olacaktır (Baltacı ve Balc1, 2017b; Bowden ve Smythe, 2009).

Bilgi uçurma süreci sosyal açıdan pek çok yarara da yol açmaktadır. Örnek vermek gerekirse bir örgütte var olan yolsuzluk veya sahtecilik vb. durumların ve örgüt faaliyetlerinin halk sağlığına veya doğaya verebileceği zararın açığa çıkarılmasına öncülük edecek bir bilgi uçurmanın sosyal etkileri önemlidir. Buna ek olarak bilgi uçurma davranışı ile hukuki ve etik ihlallerin ve hatalı davranış sergileyenlerin belirlenmesi ile etik dışı davranış sergileme potansiyeli olan iş görenlerin de sindirilmesi hedeflenmektedir (Armstrong, 2005; Miceli, 2004; Arnold ve Ponemon,1991; Mesmer-Magnus ve Viswesvaran, 2005).

\section{Bilgi Uçurma Sürecinin Yönetilmesi}

Bilgi uçuran, etik dişı eylemleri, bu tür eylemleri durdurabileceğine inandığı bir kişiye veya örgüte raporlamaktadır. Ancak bunun nasıl yapılacağına ve sürecin nasıl yürütüleceğine ilişkin belirgin bir yöntem ve davranış şekli yoktur (Park vd., 2008,929930). Örgüt içindeki hatalı edim ve eylemlerin açıklanması zannedildiği ölçüde kolay bir iş değildir (Poitras, 2014). Bu noktada bireyin sahip olduğu kişilik ve çalıştığ örgütün kültürü önem arz etmektedir (Clarkson, Van Bueren ve Walker, 2006). Örgüt çalışanları, örgüt içinde şahit oldukları etik ihlallerini başlıca üç tip tepki ile göstermektedirler (Kolarska ve Aldrich, 1980; Alford,2001):

1. Sessiz kalma veya görmezden gelme. Çalışan, etik ihlale şahit olmuştur ve durumu bilmektedir. Ancak, bu durumu yetkililere açıklamaktan ve duyurmaktan çekinmektedir (Gunsalus ve Tina,1998). Bu tür davranışın gerisinde "kinik ahlakı" ("bana dokunmayan yılan bin yıl yaşasın" veya "bana ne" "beni ilgilendirmez" felsefesi) yer almaktadır (Carson, Ellen, Verdu ve Wokutch, 2008).

2. Karşı koyma ve mücadele etme. Çalışan, örgüt içinde şahit olduğu etik dışı ve/veya hukuk dışı edim ve eylemleri, ilk olarak örgüt içinde yetkili kişi ve makamlara iletmekte ve süreci izlemektedir. Eğer çalışanda sonuç alamayacağı kanaati oluşmuşsa olayı örgüt dışındaki otoritelere bildirmektedir (Brown, 2009).

3. Kaçma. Bu tür davranışa; yalıtılma ve psikolojik şiddete maruz kalan çalışanın böyle bir duruma karşı koymayı reddetmesi ve örgüt ile ilişiğini kesmesi ve örgütten ayrılmakla sorunu çözeceğine inanması örnek olarak gösterilebilir (Chung, Monroe ve Thorne,2004).

Bilgi uçurma sürecinin yönetimi özünde bir karar verme sürecidir ve bu sürecin iyi yönetilmesi gereklidir (Graham, 1986). Şekil 4'de bilgi uçurma sürecinin yönetimini kolaylaştıran karar verme süreci görülmektedir. 


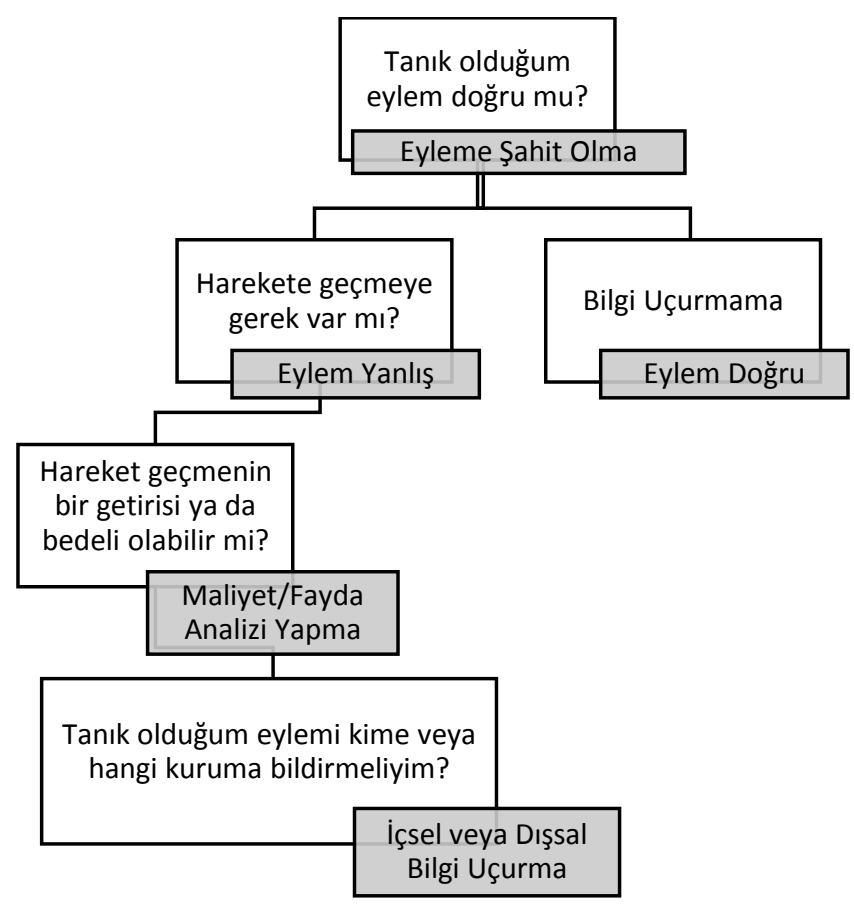

Şekil 4. Bilgi Uçurma Süreci Yönetiminde Karar Verme Aşamaları

Kaynak: Miceli, Near ve Schwenk (1991)'den uyarlanmıştır.

Şekil 4'ten hareketle, çalıştı̆̆ı örgütte herhangi bir olumsuzluğa şahit olan kişi, öncelikle tanık olduğu durumun doğruluğuna karar vermektedir. Eylem doğru ise çalışan harekete geçmemektedir, çünkü ortada bildirimde bulunulacak bir durum yoktur. Çalışan, eylemin yanlış olduğuna karar verdiğinde harekete geçmektedir. Bu noktada karar süreci bir çeşit maliyet/fayda analizine dönüşmekte, çalışan bildirimde bulunmanın olası getiri ve zararlarını yordamaya çalışacaktır. Bu aşamada çoğunlukla çalışanlar bilgi uçurmaya zaten karar vermiş durumdadırlar ve her durumda tanık oldukları olumsuzluğu açığa çıkarma konusunda kararlıdırlar (Nasu, 2015). Çalışanın bilgi uçurma kararı almasının ardından belki de en önemli seçim tanık olunan durumun kime veya hangi makamlara bildirileceğidir. Bu aşamada bilgi uçuran, karşılaşabileceği muhtemel sonuçlara odaklanmakta, örgüt içinde karşılaşabileceği olumsuzluklar (ceza, yalıtılma vb.) ile olası getirileri (ödül, terfi vb.) hesaba katmaktadır (Baltacı ve Balcı, 2017b; Miceli, Near ve Schwenk, 1991).

Şekil 4'ten de izlenebileceği üzere bilgi uçurma sürecinin yönetimi büyük ölçüde bireysel seçimlere bağlıdır (Kaptein, 2010; Baltacı ve Balcı, 2017b). Çalışanlar, etik ihlal veya olumsuzluklarla karşılaştıklarında bilgi uçurma ya da uçurmama durumunu değerlendirirler. Bilgi uçurma davranışına girişilmeden önce, şahit olunan olayın türü, sonuçlarının etkisi, olayın görülme zamanı gibi değişkenlerin değerlendirilmesi gereklidir (Miceli ve Near, 1992). Şahit olunan olayın kime, hangi kanalları kullanarak bildirileceği, bilgi uçurma sürecinin yönetilmesi açısından bilgi uçuranın karşılaştığ bir durumdur (Lindbloom, 2007). Bilgi uçurma olaylarının büyük çoğunluğunda karşılaşılan olaylar, örgüt yöneticisine, içsel bilgi uçurma mekanizmaları kullanılarak iletilmektedir (Nasu, 2015; Öztürk-Fidan, 2017). 
Bazı durumlarda örgüt yönetiminin, bilgi uçuranın bildirdiği soruna olan yaklaşımı yetersiz kalmakta, bu durumda bilgi uçurma bir üst yöneticiye yapılarak tekrarlanmaktadır (Alford, 2001). Örgüt içinde sorun çözümlenmediğinde örgüt dişına bilgi uçurulmaktadır (Jubb, 1999). Çoğu durumda dişsal bilgi uçurma, örgüt tarafından bilgi uçurana karşı çeşitli getirileri (olumsuz olarak misilleme, yalıtılma damgalama vb.; olumlu olarak kahraman ilan edilme, ödül alma vb.) olan başka bir sürecin yönetilmesini gerektirebilir (Baltacı, 2017a; Greenwood, 2015). Örgütlerde dişsal bilgi uçuranlar genellikle bu süreci iyi yönetememekte ve yaşadıkları olumsuzluklar sebebiyle örgütten ayrılmaktadırlar (Kamarunzaman, Zawawi, Hussin ve Campbell, 2012). Bununla birlikte örgüte olan adanmışlık ve yönetimin bilgi uçurana güven aşılaması gibi yönetsel stratejilerle bilgi uçuranın örgütte kalması sağlanabilir (Binikos, 2008; Fidan ve Öztürk, 2015b).

Örgüt yönetiminin, bilgi uçurma sürecinin etkili bir şekilde yönetilebilmesi için bilgi uçuranı desteklemesi, örgütte karşılaşılan etik ihlalin çözümlenebileceğine ilişkin önlemler almaya istekli olması gereklidir (Aydın, 2006). Ayrıca, bilgi uçuranın örgüt içinde yaşanabilecek her türlü istenmeyen durumdan korunacağına yönelik teminatların sağlanması da sürecin verimli bir şekilde yönetilmesi açısından önemlidir (Baltac1, 2017b; Miceli ve Near, 1985). Bu noktada örgüt yönetiminin bilgi uçurana karş1 sergilediği davranışlar, çalışanların bilgi uçurma sürecini yönetmeleri açısından elzemdir. Örgütün bilgi uçurmayı özendirici bir saydamlıkta olması, örgütte çalışanların her durumda korunacaklarını bilmeleri bilgi uçurma sürecinin istenen sonuca erişmesi açısından önemlidir (Somers ve Casal, 2011).

\section{Eğitim Örgütlerinde Bilgi Uçurma Sürecinin Yönetilmesi}

Genel olarak örgütlerde ve özelde ise eğitim örgütlerinde iş görenin etik ve hukuk dışı durumlara şahit olduğunda şu şekillerde davranım göstermesi olasıdır: kayıtsızlık, sessizlik, diğer iş görenlerle söz konusu ihlali paylaşmak, ihlal durumunu üst yönetime veya örgüt dışı otoritelere bildirmek (Park vd., 2005, 389). Bu bağlamda önem arz eden konu bilgi uçurma kavramı kapsamında hangi davranışların olması gerektiğidir. Daha önce belirtildiği üzere birey, etik ihlallerine şahit olduğunda bunları hem örgüt dâhilinde ve hem de örgüt haricinde kullanabilmektedir. Örgüt içinde bu gibi edimlerin sergilenmesi kuşkusuz etik bir çalışma ortamı oluşturulması adına önemlidir (Aydın, 2006; Baltacı, 2017c). Bununla birlikte söz konusu edimlerin örgüt dâhilinde açıklıyor olmasının, bilgi uçurma kavramı altında incelenmesi hususunda süregiden tartışmalar bulunmaktadır (Delmas, 2015; Castagnera, 2003; Nader, Petkas ve Blackwell, 1972).

Hem örgüt içinde hem de örgüt dışındaki etik ihlallerinin bildiriliyor olması çeşitli sorunlar ve tehlikeler arz etse de etik ihlalinin ifşa edilmesi durumunun örgüt dişında gerçekleştiriliyor olmasının bilgi uçurma kavramının temelini oluşturduğu ileri sürülebilir (Ray, 2006,440). Bu noktada eğitim çalışanlarının örgüt dışı otoritelere, örgütte şahit oldukları etik ihlalini bildirmeyi tercih nedeni, söz konusu etik dışı edimi düzeltme noktasında, örgüt çevresinin ve dış otoritelerin belirleyici bir güce sahip olduğu inancındandır (Park vd., 2008, 930). Böylesi bir durumda kavram çalışanın 
şahit olduğu yolsuzluk, hukuk ihlalleri veya ihmal durumlarını yöneticilerine, konuyla ilintili otoritelere ve bazı durumlarda medyaya iletmesini de içermektedir (Nasu, 2015; Lee, 2011). Böylesi geniş bir kavramsallaştırma eşliğinde eğitim örgütlerinin karmaşık doğası gereği bilgi uçurma sürecinin yönetilmesi gerek bilgi uçuran ve gerekse örgüt için önemlidir.

Eğitim örgütünde bir çalışan herhangi bir olayla karşılaştığında öncelikle eylemin niteliğine göre hareket etmektedir. Bu noktada özellikle üzerinde durulması gereken şey bireysel seçimlerdir. Bireysel seçimler çoğunlukla tanık olunan eylemin özellikleriyle ilintilidir. Şahit olunan eylemin kanıtlanabilir bir olgu olması çok önemlidir. Çünkü okullarda yaşanan en özel etik ihlal ve suçlar dahi kanıtlanamadiğı ölçüde değersizleşmektedir. Şahit olunan söz konusu eyleme ilişkin somut kanitlar veya olaya şahit olan diğer çalışanlar vs. olduğunda bilgi uçuran aktif bir tutum sergilemekte ve öncelikle içsel bilgi uçurmayı tercih etmektedir. Böylesi bir durum içsel bilgi uçurma ve ihbar mekanizmalarının aktifleştirilmesi ile sağlanacağından, güçlü ve etkin bir ihbar hattının kurulması önemlidir. Eğitim örgütlerinde çalışanların bilgi uçurmaya karar verdiklerinde, öncelikle üst makamlara başvurdukları, bu başvurudan sonuç alamazlarsa daha üst makamlara veya dişsal bilgi uçurma mekanizmalarına (medya, ALO 147 gibi) başvurdukları belirlenmiştir (Baltacı ve Balcı, 2017b; Leisinger, 2003; Lachman, 2008).

Okulların özel bir sosyal ortam olmasından hareketle, pek çok çalışan bilgi uçurma davranışına tanık olduktan sonra söz konusu durumu ailesine, iş arkadaşlarına ve hatta iş dışındaki arkadaşlarına dolaylı ya da açık bir şekilde bildirebilmektedir. Bu bildiri eylemi oldukça üstü kapalı bir şekilde gerçekleştiğinden bu durum bir bilgi uçurma olarak adlandırılamaz; çünkü doğası gereği bilgi uçurma etik dışılıkla aktif mücadele süreçlerini içermekte ve aileye bildirim ise aktif bir karşı koyma durumu olmamaktadır. Ancak eğitim çalışanının bu ilk tutumu, sonraki davranışlarını yönetmede ona yol haritası sağlayacaktır. Çalışan bu ilk bilgi alış-verişinden bilgi uçurmaya yönelik bir destek aldığında çoğunlukla durumu bildirme yönünde davranış sergilemektedir (Loyens, 2013; Martin, 2009; Moberly, 2006).

Eğitim örgütlerinde bilgi uçurma sürecini yönetmenin iki farklı durumu söz konusudur. Bunlardan ilki bilgi uçuran ve bilgi uçuranın yaşayacağı süreçlerdir. İkinci durum ise hakkında bilgi uçurulan kişi veya olayın yaşayacağı süreçtir. Bu ikinci durum aslında örgüt içindeki dengelerin seyri açısından özellikle önemlidir. Eğitim örgütlerinde bilgi uçuran kişi, okul yöneticisini ihbar ettiğinde öncelikle okul içindeki sosyal ortam ya da farklı bir ifade ile örgüt iklimi genellikle değişmektedir. Alanyazından hareketle bu değişimin çoğunlukla kaotik yönlü olduğu ve örgütlerde karmaşık bir durumun bir süre seyrettiği (Baltacı ve Balcı, 2017a; Fidan ve Balcı, 2016); ayrıca, bilgi uçuranın öncelikle yalıtıldığı görülmektedir. Bu durumun üstesinden gelmek her bilgi uçuran için kolaylıkla baş edilebilir değildir. Bunun yanında hakkında şikâyet veya ihbar durumu olan çalışan da bu süreçten çoğunlukla olumsuz etkilenmektedir. 
Gerek bilgi uçuranın ve gerekse hakkında bilgi uçurduğu kişinin yaşayacağı olumsuz etki, sürdürülebilir bir psikolojik destekle aşılabilir. Bu noktada bilgi uçurma davranışından etkilenen tüm özneler için aktif danışma ortamı oluşturulması önemlidir. Ancak bilgi uçurmanın yanlış bir davranışmış gibi algılandığı kültürlerde, gerek çalışma alanlarında ve gerekse toplum içinde böylesi destek mekanizmalarının olmadığ1 gözlemlenmiştir. Bununla birlikte alanyazında, eğitim örgütlerinde karşılaşılan pek çok etik ihlalin veya konusu suç teşkil eden durumun bildirilmediği veya bildirilmeye çekinildiği belirlenmiştir. Hal böyleyken bilgi uçurma davranışına karşı çalışanların cesaretlendirilmesi, daha saydam bir etik yönetim anlayışı oluşturmanın temelidir. Bu noktada özellikle 2000'li yıllarda hızla yaygınlaşan internet ve sosyal medya uygulamalarının pozitif yönlü etkisi olmuştur. Okullarda yaşadığ durumları internet forumlarında veya sosyal medyada paylaşan çoğu çalışan, bu durumla nasıl başa çıkacağını veya bu süreci nasıl yöneteceğini daha rasyonel bir şekilde yürütmektedir. Özellikle ALO 147 ihbar hattı ile eğitim paydaşları, eğitim örgütlerinde pozitif etik iklimin yaratıldığını deneyimlemiş olsalar da bu hatların kötü amaçlı kullanımı ile çoğu çalışan iftiraya uğramış ve itibarsızlaştırılmıştır. Özellikle ALO 147 hattına gelen ihbarların hızlı değerlendirilmesi ve çözüm odaklı yaklaşımla birlikte pek çok etik dışı uygulamanın önüne geçilmiştir. Ancak anılan kötü etkileri sebebiyle bu sistem çalışanlar üzerinde bir korku aracı olarak belirmektedir.

\section{Sonuç ve Öneriler}

En basit şekilde, örgüt içerisinde etiğe ve yasalara aykırı görülen uygulamaların, örgüt içinde veya dışında yer alan ilgili kurum ve kuruluşlara iletilmesi şeklinde tanımlanan bilgi uçurma eylemi, bireyler ve örgütler açısından aktif olarak yönetilmesi gereken ve farklı sonuçları olabilen bir süreçtir. Örgütlerde bilgi uçurma yapılması, bir yandan örgütleri daha saydam ve etkin hale getirirken, diğer yandan da örgütün var olan iklim ve imajını olumsuz yönde etkileyebilmektedir. Benzer şekilde bilgi uçurma eylemine girişen kişi (bilgi uçuran) bazen bir "kahraman" bazen de bir "hain" gibi muamele görebilmektedir. Alan yazında farklı süreçler halinde tanımlanmış olsa da bilgi uçurma süreci, özünde bir bireysel seçim ve karar alma sürecidir. Söz konusu karar alma süreci rasyonel eylemler dizgesi olarak gerçekleşmekte ve çoğu kez yoğun risk süreçlerini de içermektedir. Eğitim örgütlerinde çalışanlar, karşılaştıkları etik dışı durumları bildirirken öncelikle bu durumun doğasını düşünmektedirler. Ardından içsel veya dişsal bilgi uçurma süreci gerçekleşmektedir. Bu süreç çoğu kez çalışanın olumsuz yönde etkilenmesi ile sonuçlanmış olsa da esasen olayın bildirilmesi üst düzey bir etik davranış olarak belirmektedir.

Bilgi uçurma süreci, bilgi uçuranın olaya şahit olduğu anda başlayan aktif bir süreçtir. Şahit olma durumunu çeşitli karar süreçleri izlemektedir. Bilgi uçuran, ihbar kararı aldığında bu kararı hangi araçlarla kullanacağı da önemlidir. İçsel veya dışsal bilgi uçurma durumu bu noktada belirmektedir. İçsel bilgi uçurma örgüt içinde gerçekleşmekteyken, dişsal bilgi uçurma örgüt dışı otoritelere yapılan bildirimi temsil etmektedir. Bilgi uçurma süreci, şahit olunan etik ve hukuk dışı duruma karşı bildirimde bulunulan makamlarca eyleme geçilmesi ve sorunun çözülmesiyle son 
bulmaktadır. Bu yönüyle bilgi uçurma süreci, çatışma yönetimi ve risk yönetimi ile karar alma süreçleri gibi örgüt biliminin farklı çalışma alanlarının konusu olmaktadır.

Örgüt içinde etik ihlali ve hukuki aykırılıkların en aza indirilmesi ve bilgi uçurma davranışının görülme sıklığının artırılması için çalışanların etik eğitimlere katılımının sağlanabilir. Bunun yanında, örgüt içi standartlar, kurallar, değerler, normlar ve adaletli ödül sistemini içerek saydam bir yönetim felsefesinin örgütlerde oluşturulması ile bilgi uçurma davranışı meşru bir zemine oturtulmalıdır. Gerek örgüt içinde ve gerekse toplumda bilgi uçuranları koruyucu yasal düzenlemelere gidilmelidir. Bu amaçla örgütlerde şikâyet ve öneri mekanizmalarını arttırıcı iletişim kanalları oluşturulmalıdır. Yine bilgi uçuranları örgüt içinde yaşayabilecekleri sosyal yalıtım vb. olumsuzluklara karşı koruyucu önlemler (sosyal destek, olumlu iletişim ortamının desteklenmesi vb.) alınmalıdır.

Eğitim örgütlerinde çalışanlar arasındaki yanlış anlamalar ve diğer iletişim kaynaklı durumların çözümlenmesi ve etik farkındalık oluşturulması amacıyla okul içi iletişimin kalitesi geliştirilmeli, iyi örnekler belirlenmeli ve okullardaki iyi uygulamaların teşvik edilmesi, koçluk ve mentörlük gibi uygulamalarla iletişim kanallarının desteklenmesi sağlanmalıdır. Bilgi uçurma alanında yapılabilecek diğer çalışmalara yön vermek ve bilime katkı adına örgütlerde karşılaşılan bilgi uçurma davranışlarını yönetmek ve bilgi uçurma kavramının kişilik özellikleri, hesapverebilirlik ve diğer değişkenlerle olan ilişkilerinin araştırılması gereklidir. Kavramın veri toplanması ve ölçülmesi noktasında diğer yönetim bilimleri kavramlarına göre nispeten zorluklar içermesi sebebiyle sonraki araştırmaların karma araştırma veya nitel araştırma teknikleri kullanılarak desenlenmesi ve hatta farklı yılları içine alan boylamsal araştırmalar yapılması önerilebilir.

\section{KAYNAKLAR}

Ahern, K., ve McDonald, S. (2002). The beliefs of nurses who were involved in a whistleblowing event. Journal of Advanced Nursing, 38(3), 303-309.

Ajzen, I. (1991). The theory of planned behavior. Organizational Behavior and Human Decision Processes, vol. 50, no. 2, 179-211.

Aktan, Ç. C. (2006). Organizasyonlarda yanlış uygulamalara karşı bir sivil erdem ve ahlaki tepki ve vicdani red davranışı: whisleblowing. Mercek Dergisi. Web: http://www.sobiadacademy.net/sobem/e-yonetim/whistleblowing/aktanwhistle.pdf adresinden 27.11.2016 tarihinde alınmıştır.

Alford, F.C. (2001). Whistleblowers, Broken Lives and Organizational Power. Ithaca:Cornell University Press.

Armstrong, D. (2005). Delicate operation: how a famed hospital invests in device it uses and promotes; Cleveland Clinic set up fund that has stock in maker of heartsurgery system. Wall Street journal (Eastern ed.), A1-A16. 
Arnold, D. ve Ponemon, L. (1991). Internal auditors perceptions of whistleblowing and the influence of moral reasoning: an experiment. A Journal of Practice and Theory, 10, $1-15$.

Aselage, J., ve Eisenberger, R. (2003). Perceived organizational support and psychological contracts: A theoretical integration. Journal of Organizational Behavior, 24: 491-509.

Aydın, İ. P. (1998). Yönetsel mesleki ve örgütsel etik. Pegem Özel Eğitim ve Hizmetleri Tic. Limited Şti.

Aydın, İ. (2006). Eğitim ve Öğretimde Etik (2. Baskı) Ankara: Pegem A Yayıncılık.

Aydın, U. (2003). İş hukuku açısından işçinin bilgi uçurması (Whistleblowing). Anadolu Üniversitesi Sosyal Bilimler Dergisi.

Balcı, A., Baltacı, A., Fidan, T., Cereci, C. ve Acar, U. (2012). Örgütsel sosyalleşmenin, örgütsel özdeşleşme ve örgütsel vatandaşlıkla ilişkisi: ilköğretim okulu yöneticileri üzerinde bir araştırma. Eğitim Bilimleri Araştırmaları Dergisi-Journal of Educational Sciences Research, 2(2), 47-74.

Baltac1, A. (2016). Mentörlük ve göreve başlama. Pegem Atıf İndeksi, 289-308.

Baltaci, A., ve Balc1, A. (2017a). Complexity Leadership: A Theorical Perspective. International Journal of Educational Leadership and Management, 5(1), 3058.

Baltac1, A., ve Balc1, A. (2017b). Reasons for whistleblowing: A qualitative study. Eğitim Bilimleri Araştırmaları Dergisi - Journal of Educational Sciences Research, 7(1), 37-51.

Baltacı, A . (2017a). Avrupa Okullarında Dini Simgelerin Yasallı̆̆ı. Cumhuriyet İlahiyat Dergisi, 21 (1), 45-80.

Baltac1, A. (2017b). Relations between Prejudice, Cultural Intelligence and Level of Entrepreneurship: A Study of School Principals. International Electronic Journal of Elementary Education, 9(3).

Baltaci, A. (2017c). A Comparison of Syrian Migrant Students in Turkey and Germany: Entrepreneurial Tendencies and Career Expectations. European Journal of Educational Research, 6(1), 15-27.

Banja, J. D. (1985). Whistleblowing in physical therapy. Physical therapy,65(11), 16831686.

Bies, R., ve Moag, J. (1986). Interactional justice: Communication criteria of fairness. In R. Lewicki, B. Sheppard, ve M. Bazerman (Eds.). Research on Negotiations in Organizations (Vol. 1). Greenwich, CT: JAI Press.

Binikos, E. (2008). Sounds of silence: organisational trust and decisions to blow the whistle: empirical research. SA Journal of Industrial Psychology,34(3), 48-59.

Bouville, M. (2008). Whistle-blowing and morality. Journal of Business Ethics,81(3), 579585. 
Bowden, P. ve V. Smythe, (2009), Contemporary issues in international corporate governance, 1st edition, 112-127, Victoria: Tilde University Press.

Bowie, N. (1982). Blowing the whistle and other 'why be moral questions?, Business Ethics. Englewood Cliffs NJ: Prentice Hall. 138-149.

Brown, A.J., (2008), Whistle-blowing in the Australian public sector: Enhancing the theory and practice of internal witness management in public sector organizations, Australian National University E-Press. Web: http://epress.anu.edu.au/whistleblowing_citation.html adresinden $\quad$ 16.10.2016 tarihinde alınmıştır.

Brown, A.J., (2009), Whistle-blowing legislation in Queensland, The agenda for reform, Final report to the Queensland Government of the Australian Research Council Linkage Project: Whistling while they work: Enhancing the theory and practice of internal witness management in public sector organisations.

Carson,T.L.;Ellen,M.;Verdu,R. Ve Wokutch, E. (2008). Whistleblowing for Profit: An Ethical Analysis of Federal False Claims Act. Journal of Business Ethics,77.361-376.

Castagnera, J. O. (2003). The Rise of the Whistleblower and the Death of Privacy: Impact of 9/11 and Enron ". Labor Law Journal, 54(1), 54-65.

Chung, J., G.S. Monroe ve L. Thorne, (2004), An examination of factors affecting external and internal whistle-blowing by auditors, Web: http://www. docs.fce.unsw.edu.au/ accounting/news/ seminars 2004_s1/ paper03. pdf adresinden 12.10.2016 tarihinde alınmıştır.

Clarkson, P., A.L. Van Bueren ve J. Walker, (2006), Chief executive officer remuneration disclosure quality: Corporate responses to an evolving disclosure environment. Accounting and Finance, 46, 771-796.

Coram, P.; C. Ferguson ve R. Moroney, (2008), Internal audit, alternative internal audit structures and the level of misappropriation of assets fraud. Accounting and Finance 48, 543-559.

Cross, F. B., ve Tiller, E. H. (1998). Judicial partisanship and obedience to legal doctrine: Whistleblowing on the federal courts of appeals. Yale Law Journal, 21552176.

Davidson, R., J. Goodwin-Stewart ve P. Kent, (2005), Internal governance structures and earnings management. Accounting and Finance, 45, 241-267.

Dawson, S. (2000). Whistleblowing: a broad definition and some issues for Australia", Victoria University of Technology. Web: www.uow.edu.au/bmartin/dissent adresinden 16.11.2016 tarihinde alınmıştır.

DeGeorge, R. T. (1990). Business Ethics. (3rd ed.) New York: Mavmillan Publishing, 1990. 13.

Delk, K. L. (2013). Whistleblowing-Is it Really Worth the Consequences?.Workplace health $\mathcal{E}$ safety, 61(2), 61-64. 
Delmas, C. (2014). The Ethics of Government Whistleblowing. Social Theory and Practice, 41(1), 77-105.

De Maria, W. (1999). Deadly Disclosures: Whistle Blowing and the Ethical Meltdown of Australia. Wakefield Press.

Dozier, J. B., ve Miceli, M. P. (1985). Potential predictors of whistle-blowing: A prosocial behavior perspective. Academy of Management Review, 10(4), 823-836.

Ernst G.Jr. ve Young T., (2010), Driving ethical growth - new markets, new challenges 11th Global Fraud Survey, EYGM Limited.

Faunce, T. A. (2004). Three Australian whistleblowing sagas: lessons for internal and external regulation. Medical Journal of Australia, 181(1), 44-47.

Fidan, T., \& Balc1, A. (2016). Principal Proactivity: School Principals' Proactive. Applied Chaos and Complexity Theory in Education, 29.

Fidan, T. \& Öztürk, İ. (2015a). Perspectives and expectations of union member and non- union member teachers on teacher unions. Eğitim Bilimleri Araştırmaları Dergisi - Journal of Educational Sciences Research, 5 (2), 191-220.

Fidan, T., \& Oztürk, I. (2015b). The relationship of the creativity of public and private school teachers to their intrinsic motivation and the school climate for innovation. Procedia-Social and Behavioral Sciences, 195, 905-914.

Graham, J.W., (1986). Principled Organizational Dissent: A Theoretical Essay. In L.L. Cummings ve B.M. Staw (ed.), Research in Organizational Behaviour, Vol.8, JAI Press, Greenwich: CT,.1-52.

Greenwood, C. A. (2015). Whistleblowing in the Fortune 1000: What practitioners told us about wrongdoing in corporations in a pilot study. Public Relations Review, 41(4), 490-500.

Gunsalus, C. ve Tina K. (1998). Preventing the need for whistleblowing: practical advice for university administrators. Science and Engineering Ethics.4.75-94.

Hassink, H., M. de Vries ve L. Bollen, (2007), A content analysis of whistle-blowing policies of leading European companies. Journal of Business Ethics 75, 25-44.

Henik, E. (2008). Mad as hell or scared stiff? the effects of value conflict and emotions on potential whistleblowers". Journal of Business Ethics. Vol.80, 111-119.

Hesch, J. (2009). Whistleblowing: A guide to government reward programs. Goshen Press.

Hunt, G. (2006). The Principle of Complementarity: Freedom of Information, Public Accountability and Whistleblowing in Chapman, $R$ ve Hunt, $M$ (eds) Freedom of Information: Perspectives on Open Government in a Theoretical and Practical Context. Ashgate, Aldershot, UK.

Hwang, D., Staley, B., Te Chen, Y., ve Lan, J. S. (2008). Confucian culture and whistleblowing by professional accountants: An exploratory study. Managerial Auditing Journal, 23(5), 504-526. 
Jubb, P. B. (1999). Whistleblowing: A restrictive definition and interpretation. Journal of Business Ethics, 21(1), 77-94.

Kamarunzaman, N. Z., Zawawi, A. A., Hussin, Z. H., ve Campbell, J. K. (2012, September). Whistle blowing intention in relation to perceived organizational support, attitude to whistle blow, channel of communication among public servant. In Business, Engineering and Industrial Applications (ISBEIA), 2012 IEEE Symposium on (pp. 285-289). IEEE.

Kaptein, M., (2010), From inaction to external whistle-blowing: The influence of the ethical culture of organizations on employee responses to observed wrongdoing. Journal of Business Ethics,.

Keenan, J. P., (2007). comparing chinese and american managers on whistleblowing. Managers, Employee Responsibilities and Rights Journal. 19:85-94.

King, G. (1999). The implications of an organization's structure on whistleblowing. Journal of Business Ethics, 20(4), 315-326.

Kohn, S.M.; Kohn, Michael D; Colapinto, David K. (2004). Whistleblower Law A Guide to Legal Protections for Corporate Employees. Praeger Publishers.

Kolarska, L. ve Aldrich, H.,(1994). Exit, voice and silence: consumers' and managers' responses to organizational decline. Organizational Studies, 1980, 1 (1), .41-58.

Lachman, V. D. (2008). Whistleblowers: Troublemakers or virtuous nurses. Medsurg Nursing, 17(2), 126-128.

Larmer, R.A., (1992). Whistleblowing and employee loyalty. Journal of Business Ethics, $11,1992,125-128$.

Lee, J. (2011). Corporate Corruption \& The New Gold Mine: How the Dodd-Frank Act Overincentivizes Whistleblowing. Brook. L. Rev., 77, 303.

Leisinger, K. M. (2003). Whistleblowing und corporate reputation management. Hampp, 261-275.

Lennane, K. J. (1993). " Whistleblowing": a health issue. BMJ: British Medical Journal, 307(6905), 667.

Lewis, D. (2006) The contents of whistleblowing/ confidential reporting procedures in the uk: some lessons from empirical research. Employee Relations 28(1), 76-86.

Lindblom, L. (2007). Dissolving the moral dilemma of whistleblowing. Journal of Business Ethics, 76(4), 413-426.

Lovell, A. (2003). The enduring phenomenon of moral muteness: suppressed whistleblowing. Public Integrity, 5, 187-204.

Loyens, K. (2013). Towards a custom-made whistleblowing policy. Using grid-group cultural theory to match policy measures to different styles of peer reporting. Journal of business ethics, 114(2), 239-249. 
Macey, J. (2007). Getting the word out about fraud: a theoretical analysis of whistleblowing and insider trading. Michigan law review, 1899-1940.

Martin, B. (2009). 9 Corruption, outrage and whistleblowing. Research Companion to Corruption in Organizations, 206.

Mesmer-Magnus, J. R., ve Viswesvaran, C. (2005). Whistleblowing in organizations: An examination of correlates of whistleblowing intentions, actions, and retaliation. Journal of Business Ethics, 62(3), 277-297.

Miceli, M. P., Near, J. P., ve Schwenk, C. R. (1991). Who blows the whistle and why? Industrial \& Labor Relations Review, 45(1), 113-130.

Miceli, P. M. ve Near, J.P. (1994). Whistle-blowing: reaping the benefits. Academy of Management Executives, V. 8, I.3. 65-72.

Miceli, M. P. (2004). Whistle-Blowing Research and The Insider Lessons Learned and yet to Be Learned. Journal of Management Inquiry, 13(4), 364-366.

Miceli, M. P., Near, J. P., ve Dworkin, T. M. (2013). Whistle-blowing in organizations. Psychology Press.

Moberly, R. (2006). Sarbanes-Oxley's structural model to encourage corporate whistleblowers. Brigham Young University Law Review, 1107.

Nader, R., Petkas, P. J., ve Blackwell, K. (1972). Whistle blowing: The report of the conference on professional responsibility. Viking Pr.

Nam Dae-il ve D.J. Nepak (2007). The whistleblowing zone: applying barnard's insights to a modern ethical dilemma. Journal of Management History. Vol.13 No.1, 27-45.

Nasu, H. (2015). State Secrets Law and National Security.International and Comparative Law Quarterly, 64(02), 365-404.

Near, J.P. ve Miceli, M.P., (1985). Organizational dissidence: the case of whistleblowing. Journal of Business Ethics. 4, 1985.1-16.

Near, J. P., ve Miceli, M. P. (1995). Effective-Whistle Blowing. Academy of management review, 20(3), 679-708.

Near, J. P., Rehg, M. T., Van Scotter, J. R., \& Miceli, M. P. (2004). Does type of wrongdoing affect the whistle-blowing process?. Business Ethics Quarterly,14(02), 219-242.

O'Neill, O. (2013). Acting on principle: An essay on Kantian ethics. Cambridge University Press.

Öztürk Fidan, İ. (2017). Kenya Eğitim Sistemi: Amaç, Yapı ve Süreç Bakımından Türkiye ile Karşılaştırılması. Route Educational \& Social Science Journal. 4 (3), 1-19.

Park, H., Rehg, M. T., ve Lee, D. (2005). The influence of Confucian ethics and collectivism on whistleblowing intentions: A study of South Korean public employees. Journal of Business Ethics, 58(4), 387-403. 
Park, H.; Blenkinsopp,J.; Oktem, M. K.; Omurgonulsen, U. (2008). Cultural orientation and attidues toward different forms of whistleblowing: A comparasion of South Korea, Turkey and U.K. Journal of Business Ethics. 82. 929-939.

Poitras, L. (2014). Citizenfour. Praxis Films. Film. https://citizenfourfilm. com.

Ray, S. L. (2006). Whistleblowing and organizational ethics. Nursing ethics,13(4), 438445.

Read, W. J. ve Rama, D. V. (2003). Whistle-blowing to internal auditors. Managerial Auditing Journal, 18(5), 354-362.

Rhodes, R., ve Strain, J. J. (2004). Whistleblowing in academic medicine. Journal of medical ethics, 30(1), 35-39.

Seiffert,D.L. (2006). The influence of organizational justice on the perceived likelihood of whistleblowing. Washington State University College of Business. DOP workbook.

Sims, R. L., ve Keenan, J. P. (1998). Predictors of external whistleblowing: Organizational and intrapersonal

Somers, M., ve Casal, J. C. (2011). Type of wrongdoing and whistle-blowing: further evidence that type of wrongdoing affects the whistle-blowing process.Public Personnel Management, 40(2), 151-163.

Taylor, E.Z. ve Curtis, M.B. (2010). An examination of the layers of workplace influences in ethical judgments: whistleblowing likelihood and perseverance in public accounting. Journal of Business Ethics.93:21-37.

Trevino, L. K., ve Nelson, K. A. (2010). Managing business ethics. John Wiley \& Sons.

Tsahuridu, E. ve Vandekerckhove, W.(2008). Organisational whistleblowing policies: making employees responsible or liable? Journal of Business Ethics. 82 (1). 107-118. 